\title{
OBTAINING A SOLID SOLUTION OF CUBIC CARBIDES OF TITANIUM, VANADIUM AND MOLYBDENUM BY ELECTRIC SPARK DISPERSION
}

\author{
${ }^{1}$ Abdulazizov Tilebaldy Adilovich, candidate of chemical sciences, associate professor \\ ${ }^{2}$ Sativaldiev Abduraim Sativaldievich, professor \\ ${ }^{1}$ Osh, Osh state University \\ ${ }^{2}$ Bishkek, I. Arabaev Kyrgyz State University
}

DOI: https://doi.org/10.31435/rsglobal_ws/28022020/6923

ARTICLE INFO
Received: 11 December 2019
Accepted: 17 February 2020
Published: 28 February 2020
KEYWORDS
electrospark dispersion,
titanium, VyMozalloy,
solid solution of carbides, X-ray
phase analysis, hexane, alcohol.

\begin{abstract}
By the method of x-ray phase analysis it was found that when sparkdispersing the Ti-VyMozelectrode pair in a carbon-containing liquid medium, a condition is created for the synthesis of a solid solution of cubic carbides of titanium, vanadium and molybdenum. The metal content in the composition of the solid solution (TixVyMoz)C depends on the ratio of metals in the VyMozalloy and the nature of the liquid medium.
\end{abstract}

Citation: Abdulazizov Tilebaldy Adilovich, Sativaldiev Abduraim Sativaldievich. (2020) Obtaining a Solid Solution of Cubic Carbides of Titanium, Vanadium and Molybdenum by Electric Spark Dispersion. World Science. 2(54), Vol.1. doi: 10.31435/rsglobal_ws/28022020/6923

Copyright: (C) 2020 Abdulazizov Tilebaldy Adilovich, Sativaldiev Abduraim Sativaldievich. This is an open-access article distributed under the terms of the Creative Commons Attribution License (CC BY). The use, distribution or reproduction in other forums is permitted, provided the original author(s) or licensor are credited and that the original publication in this journal is cited, in accordance with accepted academic practice. No use, distribution or reproduction is permitted which does not comply with these terms.

In recent years, the interest of researchers in multicomponent carbide compounds of refractory transition metals has increased, since complex carbides containing two or more metals acquire higher physical, chemical and mechanical properties [1].

The preparation of multicomponent complex carbides by traditional methods is associated with certain difficulties in creating high temperatures (up to $2000{ }^{\circ} \mathrm{C}$ or more), inert or reducing atmosphere, obtaining homogeneous mixtures of individual carbides, in conducting high-speed quenching of synthesis products, etc. [2]. Therefore, the search for new methods for producing multicomponent complex carbides is relevant. In this regard, the method of electrospark dispersion is promising, since the energy of the spark discharge is sufficient to turn any metal or alloy into a liquid and vapor state [3]. High temperatures and pressures arising at the time of spark discharge create favorable thermodynamic conditions for the implementation of high-temperature synthesis of carbide compounds of refractory metals.

Therefore, the purpose of this work is to study the possibility of synthesis of a solid solution of cubic carbides of titanium, vanadium and molybdenum with the joint electrospark dispersion of titanium and an alloy of the V-Mo system.

To obtain a solid solution of carbides $\left(\mathrm{Ti}_{\mathrm{x}} \mathrm{V}_{\mathrm{y}} \mathrm{Mo}_{\mathrm{z}}\right) \mathrm{C}$ by the method of electric spark dispersion, a laboratory installation with two electrodes was used, where one electrode is a titanium plate with dimensions of $30 \times 8 \times 2 \mathrm{~mm}$, and the second electrode is an alloy $\mathrm{V}_{0,9} \mathrm{Mo}_{0,1}$ or an alloy $\mathrm{V}_{0,2} \mathrm{Mo}_{0,8}$ in the form of a rod with dimensions of 20x6x $5 \mathrm{~mm}(0.9 ; 0.8 ; 0.2$ and 0.1 - atomic fractions of metals in the alloy). A spark discharge is created using an $\mathrm{RC}$ generator with the following electrical parameters: voltage $\mathrm{U}=220 \mathrm{~V}$, capacitance of the capacitor $\mathrm{C}=2 \mathrm{UF}$, i.e. with the energy of a single spark discharge $\mathrm{E}=0.05 \mathrm{j}$. The synthesis of carbide compounds was carried out in hexane and ethyl alcohol (96\%), 
which contain a certain amount of carbon. Hexane and alcohol serve as a carbon supplier for the synthesis of carbide compounds under spark discharge conditions.

Alloys of the V-Mo system with a certain ratio of metals (through the 10th atom. \%) were melted on electron beam installation by power an electron beam up to $12.5 \mathrm{~kW}$ from electrolytic vanadium and ceramic-metal molybdenum.

The products of joint electrospark dispersion of titanium and alloys of the V-Mo system are contained in the solid phase; therefore, the solid phase was separated from the liquid phase in a centrifuge and dried at $70-80{ }^{\circ} \mathrm{C}$.

The phase composition of the obtained products was studied by $\mathrm{x}$-ray phase analysis. The diffraction patterns of the products were recorded on a DRON-3 diffractometer with filtered copper radiation. The diffraction patterns were calculated according to the procedure [4].

$\mathrm{X}$-ray diffraction patterns of the products of joint electrospark dispersion of titanium and alloys of the V-Mo system in hexane and alcohol are presented in Figs. 1, 2, and the results of their calculation are shown in Tables 1, 2.

An analysis of the diffraction patterns of the products of joint electrospark dispersion of titanium with alloys $\mathrm{V} 0.9 \mathrm{Mo} 0.1$ and $\mathrm{V} 0.2 \mathrm{Mo} 0.8$ in hexane and alcohol shows that the products, regardless of the composition of the alloy of the V-Mo system and the nature of the liquid medium, consist of two phases (Fig. 1,2).

The main phase is a face-centered cubic (fcc) $\mathrm{NaCl}$ type lattice. Therefore, this phase is a solid solution of cubic monocarbides of titanium, vanadium and molybdenum $\left(\mathrm{Ti}_{\mathrm{x}} \mathrm{V}_{\mathrm{y}} \mathrm{Mo}_{\mathrm{z}}\right) \mathrm{C}$. For the same system of titanium-alloy $\mathrm{V}_{\mathrm{x}} \mathrm{Mo}_{\mathrm{y}}$, complex carbides $\left(\mathrm{Ti}_{\mathrm{x}} \mathrm{V}_{\mathrm{y}} \mathrm{Mo}_{\mathrm{z}}\right) \mathrm{C}$ synthesized
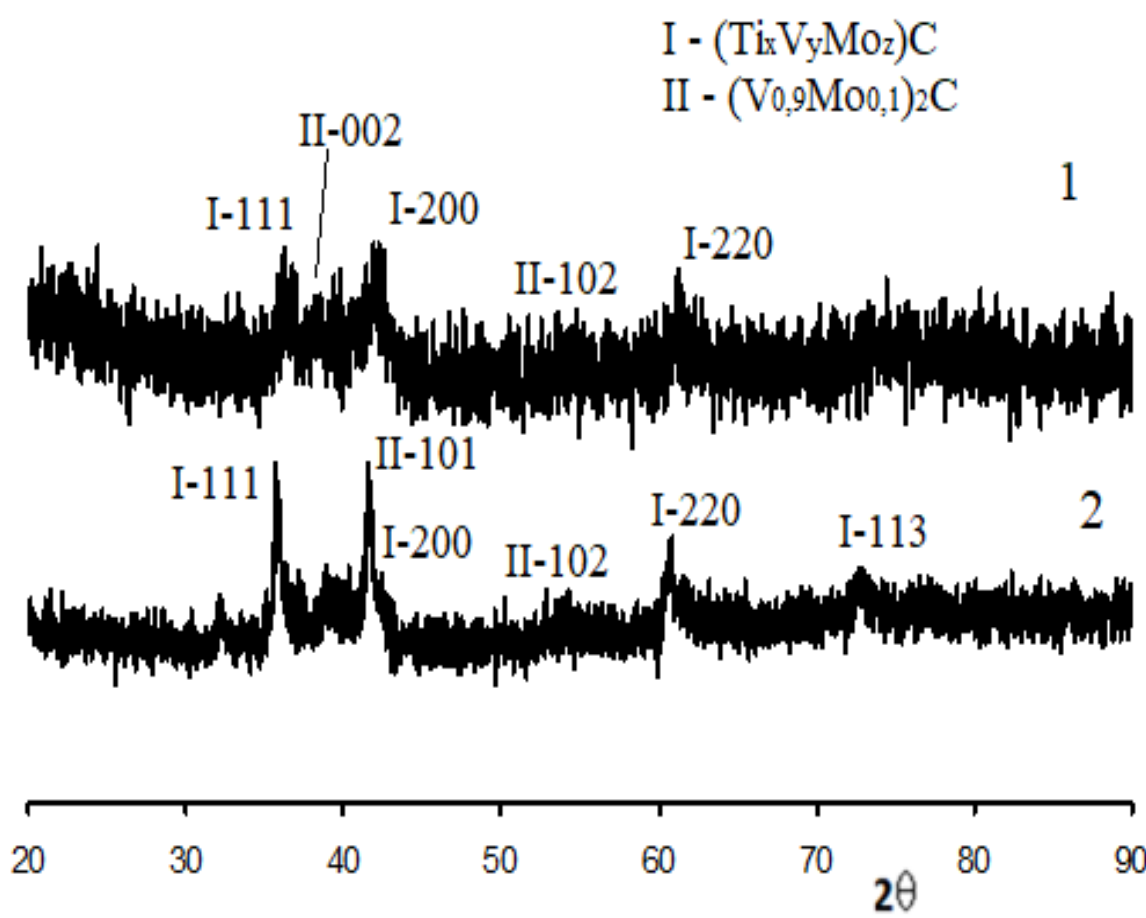

Fig. 1. X-ray diffraction patterns of the products of joint electrospark dispersion of titanium and $V_{0,9} M o_{0,1}$ alloy in hexane (1) and alcohol (2)

In hexane and alcohol differ in the lattice parameter, i.e. by metal content. The complex carbides $\left(\mathrm{Ti}_{\mathrm{x}} \mathrm{V}_{\mathrm{y}} \mathrm{Mo}_{\mathrm{z}}\right) \mathrm{C}$ obtained by the joint electric-spark dispersion of the $\mathrm{Ti}-\mathrm{V}_{0,9} \mathrm{Mo}_{0,1}$ and $\mathrm{Ti}-\mathrm{V}_{0,2} \mathrm{Mo}_{0,8}$ systems in hexane are characterized, respectively, with the following lattice parameter $\mathrm{a}=4,275 \mathrm{~A}^{\circ}$ and $\mathrm{a}=4.310 \mathrm{~A}^{\circ}$, and the resulting in alcohol, complex carbides have the following lattice parameter a $=4.260 \mathrm{~A}^{\circ}$ and $\mathrm{a}=4.300 \mathrm{~A}^{\circ}$ (Tables 1,2). Based on the lattice parameters, it can be assumed that four-component complex carbides are formed in hexane, where the titanium content is much lower than vanadium and molybdenum, and complex carbides with a higher titanium content are formed in alcohol. Perhaps this is due to the different dispersibility of titanium and alloys $\mathrm{V}_{0,9} \mathrm{Mo}_{0,1}$, and $\mathrm{V}_{0,2} \mathrm{Mo}_{0,8}$. The dispersibility of titanium in both liquid media is higher than that of alloys, but the dispersibility of titanium is higher in alcohol (table.3). 
Table 1. The results of the calculation of the diffraction patterns of the products of joint electrospark dispersion of titanium and alloy $\mathrm{V}_{0,9} \mathrm{Mo}_{0,1}$ in hexane and alcohol

\begin{tabular}{|c|c|c|c|c|c|c|c|}
\hline \multirow[t]{3}{*}{ № } & \multicolumn{2}{|c|}{ Experimental data } & \multicolumn{5}{|c|}{ Phase Composition } \\
\hline & \multirow[t]{2}{*}{ I } & \multirow[t]{2}{*}{$\mathrm{d}, \mathrm{A}^{0}$} & \multicolumn{2}{|c|}{$\left(\mathrm{Ti}_{\mathrm{x}} \mathrm{V}_{\mathrm{y}} \mathrm{Mo}_{\mathrm{z}}\right) \mathrm{C}$} & \multicolumn{3}{|c|}{$\left(\mathrm{V}_{0,9} \mathrm{Mo}_{0,1}\right)_{2} \mathrm{C}$} \\
\hline & & & hkl & $\mathrm{a}, \mathrm{A}^{0}$ & hkl & $\mathrm{a}, \mathrm{A}^{0}$ & $\mathrm{c}, \mathrm{A}^{0}$ \\
\hline \multicolumn{8}{|c|}{ Hexane } \\
\hline 1 & 71 & 2,4651 & 111 & 4,269 & & & \\
\hline 2 & 69 & 2,3066 & & & 002 & & 4,613 \\
\hline 3 & 63 & 2,2736 & & & 101 & 2,912 & 4,615 \\
\hline 4 & 100 & 2,1423 & 200 & 4,284 & & & \\
\hline 5 & 47 & 1,6972 & & & 102 & 2,912 & 4,615 \\
\hline 6 & 81 & 1,5104 & 220 & 4,272 & & & \\
\hline \multicolumn{8}{|c|}{ Alcohol } \\
\hline 1 & 70 & 2,4553 & 111 & 4,252 & & & \\
\hline 2 & 44 & 2,3070 & & & 002 & & 4,614 \\
\hline 3 & 100 & 2,2678 & & & 101 & 2,911 & 4,612 \\
\hline 4 & 55 & 2,1331 & 200 & 4,266 & & & \\
\hline 5 & 25 & 1,6801 & & & 102 & 2,911 & 4,612 \\
\hline 6 & 28 & 1,5070 & 220 & 4,262 & & & \\
\hline 7 & 48 & 1,2848 & 113 & 4,261 & & & \\
\hline
\end{tabular}

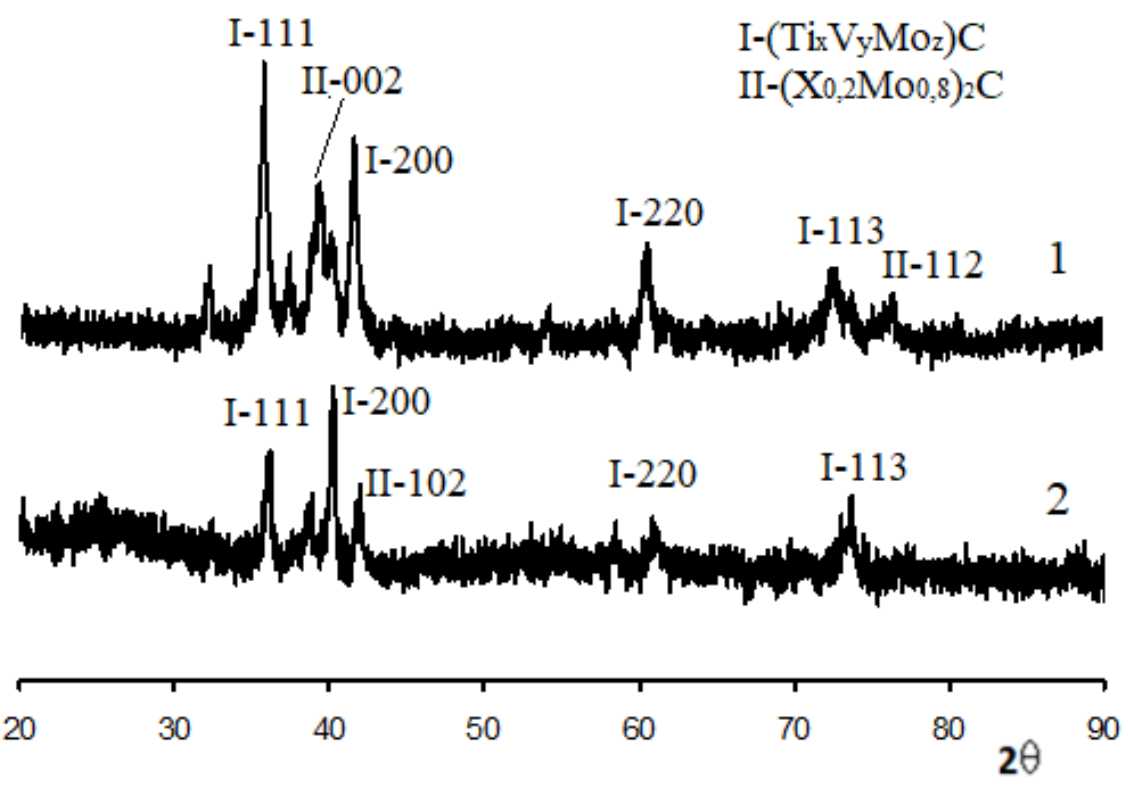

Fig. 2. X-ray diffraction patterns of the products of joint electrospark dispersion of titanium and alloy $V_{0,2} \mathrm{Mo}_{0,8}$ in hexane (1) and alcohol (2)

Table 2. Results of calculation of diffractograms of products of joint electric spark dispersion of titanium and alloy $\mathrm{V}_{0,2} \mathrm{Mo}_{0,8}$ in hexane and alcohol

\begin{tabular}{|c|c|c|c|c|c|c|c|}
\hline \multirow[t]{3}{*}{ № } & \multicolumn{2}{|c|}{ Experimentaldata } & \multicolumn{5}{|c|}{ PhaseComposition } \\
\hline & \multirow[t]{2}{*}{ I } & \multirow[t]{2}{*}{$\mathrm{d}, \mathrm{A}^{0}$} & \multicolumn{2}{|c|}{$\left(\mathrm{Ti}_{\mathrm{x}} \mathrm{V}_{\mathrm{y}} \mathrm{Mo}_{\mathrm{z}}\right) \mathrm{C}$} & \multicolumn{3}{|c|}{$\left(\mathrm{V}_{0,2} \mathrm{Mo}_{0,8}\right)_{2} \mathrm{C}$} \\
\hline & & & hkl & $\mathrm{a}, \mathrm{A}^{0}$ & hkl & $\mathrm{a}, \mathrm{A}^{0}$ & $\mathrm{c}, \mathrm{A}^{0}$ \\
\hline 1 & 2 & 3 & 4 & 5 & 6 & 7 & 8 \\
\hline \multicolumn{8}{|c|}{ Hexane } \\
\hline 1 & 100 & 2,4891 & 111 & 4,311 & & & \\
\hline 2 & 64 & 2,3547 & & & 002 & & 4,709 \\
\hline 3 & 39 & 2,2692 & & & 101 & 2,992 & 4,712 \\
\hline 4 & 79 & 2,1545 & 200 & 4,309 & & & \\
\hline 5 & 11 & 1,7414 & & & 102 & 2,992 & 4,712 \\
\hline 6 & 37 & 1,5241 & 220 & 4,311 & & & \\
\hline
\end{tabular}


Continuation of table 2 .

\begin{tabular}{|l|c|c|c|c|c|c|c|}
\hline 1 & 2 & 3 & 4 & 5 & 6 & 7 & 8 \\
\hline 7 & 26 & 1,2989 & 113 & 4,308 & & & \\
\hline 8 & 22 & 1,2824 & \multicolumn{7}{|c|}{ Alcohol } \\
\hline \multicolumn{7}{|l|}{} \\
\hline 1 & 87 & 2,4851 & 111 & 4,304 & & 2,993 & 4,711 \\
\hline 2 & 42 & 2,3528 & & & 002 & & 4,706 \\
\hline 3 & 31 & 2,2669 & & & 101 & 2,993 & 4,714 \\
\hline 4 & 100 & 2,1549 & 200 & 4,300 & & & \\
\hline 5 & 29 & 1,7401 & & & 102 & 2,993 & 4,714 \\
\hline 6 & 44 & 1,5196 & 220 & 4,298 & & & \\
\hline 7 & 31 & 1,2957 & 113 & 4,297 & & & \\
\hline
\end{tabular}

Table 3. Dependence of the lattice parameter of complex carbides $\left(\mathrm{Ti}_{\mathrm{x}} \mathrm{V}_{\mathrm{y}} \mathrm{Mo}_{\mathrm{z}}\right) \mathrm{C}$ on the composition of the $\mathrm{V}_{\mathrm{y}} \mathrm{Mo}_{\mathrm{z}}$ alloy and the nature of the liquid medium

\begin{tabular}{|c|c|c|c|c|l|}
\hline № & System & Fluidmedium & Latticeparameter, $\mathrm{A}^{\mathrm{o}}$ & $\begin{array}{c}\text { Molarratio } \\
\mathrm{Ti} / \mathrm{V}_{\mathrm{y}} \mathrm{Mo}_{z}\end{array}$ & Compositecarbide \\
\hline 1. & $\mathrm{Ti}^{-} \mathrm{V}_{0,9} \mathrm{Mo}_{0,1}$ & Hexane & 4,275 & $1,5 / 1$ & $\left(\mathrm{Ti}_{0,65} \mathrm{~V}_{0,31} \mathrm{Mo}_{0,04}\right) \mathrm{C}$ \\
\hline 2. & $\mathrm{Ti}-\mathrm{V}_{0,9} \mathrm{Mo}_{0,1}$ & Alcohol & 4,260 & $1,5 / 1$ & $\left(\mathrm{Ti}_{0,55} \mathrm{~V}_{0,40} \mathrm{Mo}_{0,05}\right) \mathrm{C}$ \\
\hline 3. & $\mathrm{Ti}^{-} \mathrm{V}_{0,2} \mathrm{Mo}_{0,8}$ & Hexane & 4,310 & $2 / 1$ & $\left(\mathrm{Ti}_{0,75} \mathrm{~V}_{0,05} \mathrm{Mo}_{0,20}\right) \mathrm{C}$ \\
\hline 4. & $\mathrm{Ti}_{-} \mathrm{V}_{0,2} \mathrm{Mo}_{0,8}$ & Alcohol & 4,300 & $1 / 1,5$ & $\left(\mathrm{Ti}_{0,60} \mathrm{~V}_{0,08} \mathrm{Mo}_{0,32}\right) \mathrm{C}$ \\
\hline
\end{tabular}

The second phase of the products are also complex carbide based on vanadium and molybdenum $\left(\mathrm{V}_{\mathrm{y}} \mathrm{Mo}_{\mathrm{z}}\right)$ semi-carbides $2 \mathrm{C}$ with hexagonal density-packed (GPU) lattice. Complex carbides synthesized in hexane and alcohol differ in the value of lattice parameters. Complex carbides obtained in hexane have higher values of lattice parameters than complex carbides obtained in alcohol.

It was shown in [5] that, when electrospark dispersing an alloy of the V-Mo system in heptane, complex carbide $\left(\mathrm{V}_{\mathrm{y}} \mathrm{Mo}_{\mathrm{z}}\right) \mathrm{C}$ with a face-centered cubic lattice is formed and the lattice parameter of this complex carbide varies linearly with the alloy composition. According to the authors, when electrospark dispersing alloys $\mathrm{V}_{0,9} \mathrm{Mo}_{0,1}$ and $\mathrm{V}_{0,2} \mathrm{Mo}_{0,8}$, complex carbides are formed $\left(\mathrm{V}_{0,9} \mathrm{Mo}_{0,1}\right) \mathrm{C}$ and $\left(\mathrm{V}_{0,2} \mathrm{Mo}_{0,8}\right) \mathrm{C}$ with the corresponding lattice parameter $\mathrm{a}=4.180 \mathrm{~A}^{\circ}$ and $4.258 \mathrm{~A}^{\mathrm{o}}$.

The solid solution of carbides $\left(\mathrm{Ti}_{\mathrm{x}} \mathrm{V}_{\mathrm{y}} \mathrm{Mo}_{\mathrm{z}}\right) \mathrm{C}$ can be considered as a quasibinary system where complex carbide $\left(\mathrm{V}_{\mathrm{x}} \mathrm{Mo}_{\mathrm{y}}\right) \mathrm{C}$ is dissolved in cubic titanium monocarbide. Assuming that the lattice parameter of the solid solution $\left(\mathrm{Ti}_{\mathrm{x}} \mathrm{V}_{\mathrm{y}} \mathrm{Mo}_{\mathrm{z}}\right)$ Clinearly depends on the content of titanium carbide $\mathrm{TiC}$ and complex carbide $\left(\mathrm{V}_{\mathrm{y}} \mathrm{Mo}_{\mathrm{z}}\right) \mathrm{C}$, and taking into account the dispersibility of titanium and $\mathrm{V}_{\mathrm{y}} \mathrm{Mo}_{\mathrm{z}}$ alloys, an approximate composition of this solid solution synthesized in heptane is established. The complex carbide formed during the joint electric-spark dispersion of titanium and the $\mathrm{V}_{0,9} \mathrm{Mo}_{0,1}$ alloy in heptane has the following composition $\left(\mathrm{Ti}_{0,65} \mathrm{~V}_{0,31} \mathrm{Mo}_{0,04}\right) \mathrm{C}$, and when the Ti- $\mathrm{V}_{0,2} \mathrm{Mo}_{0,8}$ system is spark-dispersed in complex heptane, a complex carbide of the composition $\left(\mathrm{Ti}_{0,75} \mathrm{~V}_{0,05} \mathrm{Mo}_{0,20}\right) \mathrm{C}$ (Table 3). Complex carbides $\left(\mathrm{Ti}_{\mathrm{x}} \mathrm{V}_{\mathrm{y}} \mathrm{Mo}_{\mathrm{z}}\right) \mathrm{C}$ synthesized by electrospark dispersion of Ti-VMo systems in alcohol contain less titanium than complex carbides $\left(\mathrm{Ti}_{\mathrm{x}} \mathrm{V}_{\mathrm{y}} \mathrm{Mo}_{\mathrm{z}}\right) \mathrm{C}$ obtained in hexane.

Thus, when electrospark dispersing the $\mathrm{Ti}^{\mathrm{V}}-\mathrm{V}_{\mathrm{y}} \mathrm{Mo}_{\mathrm{z}}$ electrode pair in a carbon-containing liquid medium, a condition is created for the synthesis of a solid solution of cubic carbides of titanium, vanadium and molybdenum. The metal content in the composition of the solid solution of carbides $\left(\mathrm{Ti}_{\mathrm{x}} \mathrm{V}_{\mathrm{y}} \mathrm{Mo}_{\mathrm{z}}\right) \mathrm{C}$ depends on the ratio of metals in the $\mathrm{V}_{\mathrm{y}} \mathrm{Mo}_{\mathrm{z}}$ alloy and the nature of the liquid medium.

\section{REFERENCES}

1. Khollek H. Double and triple carbide and nitride transition metal systems: Reference: [Text] / X Hollek. M.: Metallurgy, 1988. - 319 p.

2. Samsonov G.V., UpadhayaG.Sh., Neshpar V.S. Physical material science of carbides [Text] / G.V. Samsonov, G.Sh. Upadhaya, V.S. Nashpar. - M.: Metallurgy, 1976. - 455s.

3. Sativaldiev A. Electroerosive synthesis of transition metal compounds [Text] / A. Sativaldiev, U.A. Asanov. - Bishkek: KGNU, 1995. - 187 p.

4. Mirkin L.I. X-ray analysis. Reference guide. Obtaining and measuring radiographs [Text] / L.I. Mirkin. M.: Nauka, 1976. - 326 p.

5. Abdulazizov T.A. Synthesis of solid solutions of titanium and vanadium monocarbides under conditions of electrospark dispersion [Text] / T.A. Abdulazizov, O.R. Abdullaeva. Republican scientific - theoretical journal "Proceedings of the Kyrgyz Republic" No. 11.- Bishkek, 2017. C. 6-8. 